\title{
Municipalidad y Administración Local, antecedentes a la Constitución del Ayuntamiento de Melilla
}

\section{Francisco Saro Gandarillas}

Es razonable pensar que Melilla, desde siempre plaza fronteriza y militar, tenfa confundida su administración local dentro del fuero militar, dada la imposibilidad, de hecho, de separar lo estrictamente militar de lo civil en una fortaleza cuya población eran en la práctica, guarnición o personas afectas por trabajo o familia a la misma. De otro lado, su escasa población exigía unos mínimos servicios comunes para atención de sus necesidades cotidianas, necesidades que, a su vez, fueron satisfechas, por la casa ducal de Medina Sidonia hasta 1556, y por el Estado desde esa fecha. Si a esto unimos el hecho de que Melilla debió perder interés para unos hipotéticos pobladores de la zona al caer en manos de los fronterizos los fuertes exteriores -Muley Ismail- a finales del siglo XVII y, con ello, perderse la teórica posibilidad de una futura expansión territorial, y si, además, desde los inicios del siglo XVIII, se incrementa en plaza el número de confinados, gente que, al mismo tiempo que se hacen cargo de las obras, introducen un elemento de inestabilidad interior que debió hacer poco atractiva la permanencia en ésta, por todo ello no tiene nada de extraño que, en esas circunstancias, la población libre de Melilla quedara estabilizada en una cantidad mínima, con escasos altibajos hasta mediados del siglo XIX. A su vez, el Estado no favorecía el asentamiento de personal civil en unas plazas en permanente estado de alerta militar, prohibiendo o limitando, durante los siglos XVIII y parte del XIX la llegada de otras gentes que no fueran la de su guarnición y empleados de plantilla.

Asf, el 30 de septiembre de 1800 , la población de Melilla se componía de 104 jefes, oficiales y empleados de plantilla fija y guarnición ordinaria y extraordinaria, 867 de tropa, 1.000 desterrados y 224 mujeres, niños y criados, éstos últimos, suponemos familiares del personal de la guarnición y empleados, según estado existente en un Plano de la época actualmente en la Comandancia de Obras de esta ciudad, población aquélla que no des- 
taca sobre la totalizada en estados anteriores y posteriores hasta bien entrado el siglo XIX. están

Las noticias que Morales nos da sobre población son fragmentarios y a la espera de alguien que quiera tomar el testigo y completar las lagunas existentes hasta donde se pueda, excesivas lagunas que crean serias dudas sobre el número y tipo de población de Melilla hasta la confección de los primeros padrones conocidos, ya creada la Junta de Arbitrios.

En cualquier caso, los datos que tenemos nos hacen pensar que la escasez de población civil autónoma no permitía o no hacía necesaria la creación de un organismo municipal que administrara un patrimonio común o unos servicios en su mayor parte inexistentes al estar afectos al ramo de Guerra en su totalidad y localizados en un espacio tan reducido como es el primer recinto de la Plaza.

Por eso vemos que los primeros intentos de creación de juntas con cierto carácter municipal, desde 1845, fueron, o bien efímeros, o bien, contaban entre sus atribuciones actividades que poco o nada tenía que ver con las que normalmente se asignan a una corporación de carácter civil, puđiéndose comprobar que aquéllas no pueden desprenderse en ningún momento de su condición de organismo militar en consonancia con lo que realmente era Melilla: un gran acuertelamiento en el que excepcionalmente vivía en su interior una cierta cantidad de personal civil vinculado a aquél. El hecho de que a partir de 1849 encontremos establecido un arbitrio sobre cantinas y tiendas de comestibles, lo que parece darle una cierta atribución propia de municipio, no hace sino marcar la singularidad de las Juntas, sin por ello hacerle perder su carácter esencialmente militar, más cercanas a una Junta Económica de Plaza que a una corporación administrativa local. Obsérvese que en su composición entran generalmente el Gobernador Militar, Comandante de Ingenieros, Comandante de Artillerfa, Mayor de Plaza, Comisario de Guerra y jefes de los distintos cuerpos de la guarnición, estructura que se mantienen, con variaciones poco relevantes, hasta 1902 , año en que entran a formar parte de aquélla, con carácter fijo, elementos civiles. Por otra parte, todas las iniciativas de las citadas Juntas pasan a través del Capitán General de la Región quien, en su caso, las hace llegar a su vez, hasta el Ministro de la Guerra, quien en última instancia, dispone y regula aquéllas, desvinculado de cualquier otro organismo civil.

Por. R. O. de 17 de febrero de 1864 quedan derogadas aquellas disposiciones que limitaban la llegada y permanencia de personal no militar en la plaza, con el fin de repoblar el nuevo territorio conseguido, al menos de forma nominal, tras el formal establecimiento de los nuevos límites de $\mathrm{Me}$ lilla. La Real Orden complementaba la ley de creación del puerto franco de 1863 , ley que también trafa pretensiones de revitalizar el territorio añadido, dando el impulso económico necesario para conseguir una repobla- 
ción obligada. Ambas disposiciones, bajo esta óptica, resultaron en un principio fallidas. Sin embargo, aunque muy lentamente, la población fue aumentando, gracias al progresivo incremento comercial con las cabilas cercanas y los nuevos contingentes militares que amplían la guarnición a lo largo de la segunda mitadl del siglo. Hacia 1879, la guarnición oscilaba sobre los 2.000 individuos, incluyendo el penal, dando la población civil una cifra de 636 almas, cerca del triple de la existente en 1800. El crecimiento, como se ve, fue más bien lento.

Tras la visita a Melilla, el 25 de octubre de 1878, del Capitán General de la Región, General Predergast, la antigua y vacilante Junta Municipal quedó reorganizada, siguiendo como Presidente el Gobernador Militar y como vocales los jefes de la guarnición, Comandante de Artillerfa, Comandante de Ingenieros, Sargento Mayor de Plaza, Jefe de Sanidad Militar, Comisario de Guerra, Vicario Castrense y Asesor Jurídico Militar. Aún con leves cambios en su composición, la nueva Junta apenas varió su carácter. Segúa dependiendo del ramo de Guerra y no tenía personalidad jurídica propia. Conservaba la costumbres, establecida unos años antes, de solicitar la participación de tres civiles, comerciantes 0 industriales establecidos en la plaza, pero exclusivamente para la confección del presupuesto de gastos e ingresos. Así nacía la polémica Junta de Arbitrios, cuyo nombre indicaba muy explícitamente cuál serfa la base económica de su funcionamiento, legado que llega hasta nuestros días.

Curiosamente, la Jun ta conservó el nombre de Municipal hasta la sesión del 27 de junio de 1880 en que definitivamente adopta el de Junta de Arbitrios, nombre que mantendrá durante cuarenta y siete años. La primera reunión se celebra el 25 de mayo de 1879. Desde esa fecha se conservan los libros de actas en el Archivo Municipal lo que en cierto modo da al organismo un carácter formal que anteriormente no tenía. Excepcionalmente -como hemos dicho- y como elementos de información, participan en esta primera Junta tres comerciantes de la plaza en las especialidades de tejidos, bebidas y tabacos. Se pretendía partir de una base seria para el establecimiento de los nuevos arbitrios de financiación de la Junta y posterior confección del presupuesto. Estos presupuestos debían ser aprobados por el Ministro de la Guerra.

El sistema contable, muy simple, se basaba en una cuenta de cargo y data, con arqueo mensual, a cargo de un oficial de la Administración Militar como tesorero.

Fuentes de ingresos eran el gravamen sobre importaciones de tejidos, sobre algunos tipos de bebidas alcohólicas, sobre tabacos y sobre mercancías procedentes del campo marroquí como pieles, huevos y cera en panes. En la práctica, este tipo de ingresos suponfan cantidades mínimas con las que apenas habia para el sostenimiento de las necesidades urbanas más inmediatas. Por eso, obras tan indispensables como el alcantarillado de 
la plaza, se prolongaban durante años al no ser suficientes los ingresos para terminarlas en un solo ejercicio económico. Las tasas fueron aumentadas y diversificadas posteriormente con oposición de los sectores afectados, quienes sostenian que los arbitrios enmascaraban la inoperancia de la ley del puerto franco.

Como consecuencia del gradual aumento de población, la Junta amplía sus atribuciones al estudio y consideración de las presiones urbanas que inducen un ensanche de la plaza, excesivamente comprimida ya dentro de los estrechos límites del viejo recinto. La consideración de una próxima expansión urbana constituye un salto cualitativo importante que nos hace ver de forma distinta a la nueva Junta en contraste con las anteriores. El potencial crecimiento urbano debía adaptarse necesariamente al proyecto de ensanche $y$ mejora de las fortificaciones y población de la plaza de Melilla, aprobado por R. O. de 25 de enero de 1868, quedando aquélla férreamente limitada por las necesidades militares y, sobre todo, por la vieja Ley de Zonas de 1845; en cualquier caso, se iniciaba la futura expansión urbana de la ciudad, expansión que tanta influencia habría de tener en el funcionamiento de la Junta de Arbitrios y en su composición posterior.

En junio de 1880 se decide dotar a la plaza de un facultativo médico titular, función hasta ese momento a cargo.de Sanidad Militar, cometido que sigue conservando cierto tiempo a través de los médicos militares, pero ya con un carácter mu nicipal.

En 1883, con cargo a la Junta, se comienza el desembarcadero de la Marina o muelle del comercio, se continúan las obras de alcantarillado y empedrado de la plaza. El presupuesto de ese año, ciertamente exiguo, alcanzaba las 70.360 pesetas. Seis años más tarde apenas se había incrementado, ascendiendo a una cantidad de 73.320 pesetas, para atender a las necesidades de una población de 1.875 personas, doble de la de 1883 . Desde la R. O. de 22 de septiembre de 1883 la Junta se regfa por un reglamento, aprobado en esa fecha, y que serviría de inspiración a reglamentos posteriores.

Por la imperiosa necesidad de recaudar fondos para subvenir a las perentorias necesidades de una población en expansión, en alguna ocasión es preciso recurrir a medios extraordinarios, que hoy, con perspectiva de cien años, nos pueden parecer incomprensibles. Ası́, en escrito de 15 de febrero de 1885, el Capitán General de Granada autoriza a la Junta para que dé vía libre a la venta de armas a las cabilas cercanas. Podemos especular que con esta autorización se pretendía el doble fin de evitar el contrabando costero y allegar los fondos imprescindibles para las arcas exhaustas. Este debe ser sin duda el origen de algunas leyendas que aún hoy corren de boca en boca por Melilla sobre supuestas complicidades de autoridades en el contrabando de armas, leyendas carentes de fundamentos y que fueron aireadas por Ciges Aparicio en 1932. La venta de armas de guerra fue 
prohibida en julio de 1888 , continuándose con las de caza y revólver únicamente.

En marzo de 1887 el Capitán General ordena el nombramiento de un arquitecto mu nicipal, funcionario retribuido, para las obras a cargo del municipio. Se nombra al que ostentaba el cargo, en la práctica, desde la creación de la Junta, Comandante de Ingenieros don Eligio Souza, autor de los primeros proyectos de la corporación hasta 1893. El cargo, que combina al mismo tiempo arquitectura e ingenierf́a, será desempeñado hasta 1928 por ingenieros militares.

En aquel mismo año se crean secciones de orden Público y polícia, con gratificación a cargo de la Junta, antedecentes de la actual Policfa Municipal.

Se comienzan los pabellones de la calle Ledesma con cargo a 15.000 pesetas iniciales dadas por la Junta para el objeto, precedente de una serie de construcciones en esta línea que culminan en 1900 con los pabellones militares del Buen Acuerdo y en 1903 con los pabellones de Orozco (altual Comandancia General).

En 1887 comienza a prestar sus servìcios el primer médico civil de Melilla, titular de la Junta.

Sucesivamente se inician o continúan obras como alcantarillado, muelles, cementerio, escuelas, carreteras, tinglado del puerto, fuentes públicas, fuerte del Polígono, ampliándose día a día las actividades que abarca la corporación. Se pone en funcionamiento un Centro Higiénico, redactándose un Reglamento de Salubridad.

Al quedar superado el Reglamento de 1883 , se ordena por la autoridad regional su revisión, aprobándose el nuevo en sesión del 25 de mayo de 1892 . Para este año el presupuesto de la Junta alcanzaba las 206.605 pesetas, estructurándose en las siguientes secciones: Vigilancia / Policra / Aguas / Alumb rado / Obras / Instrucción e Higiene. Apenas un año antes se habian terminado los barrios del Mantelete y Polígono, saliéndose, por primera vez, de los límites del cuarto recinto.

Antes de comenzar la campaña de 1893, Melilla tiene una población -según el padrón de marzo de ese año- de 3.031 habitantes, sin incluir guarnición ni penal. Tras el comienzo de la guerra, la llegada de 22.000 soldados trajo consigo un espectacular aumento de población civil y un aumento, no menos espectacular, de necesidades urgentes a resolver, necesidades que sobrepasan con mucho a las posibilidades económicas de la Junta.

En aquel momento los ingresos con que cuenta la Junta de Arbitrios para atender sus funciones eran:

a) Los arbitrios sobre artículos de importación, tanto de procedencia exterior como del campo fronterizo. Quedan libres de arbitrios los 
comestibles que se consumen en la plaza y tejidos para uso de la población local.

b) Impuestos sobre bebidas alcohólicas

c) Venta de sepulturas en el nuevo cementerio.

d) Cesión de solares en el nuevo barrio del Polígono (0,05 pts. del canón).

e) Multas por infracciones.

f) Inscripción de perros.

g) Contribución sobre puestos de venta de carne.

h) Contribución por alquiler del tinglado del muelle para depósito de mercancías.

i) Otros de pequeña importancia (rentas, legados, etc.).

$\mathrm{Ni}$ que decir tiene que el concepto de mayor importancia es el correspondiente al apartado a), concepto que, aunque continuado en el tiempo, estaba muy condicionado a los avatares del comercio e industria locales, variables según las condiciones del campo fronterizo, cuantía de la guarnición militar y, en el futuro próximo, campañas relacionadas con la intervención de España en Marruecos y posterior protectorado, circunstancias que, con distinto nombre, siguen dándose en la actualidad, y que están esperando una persona arriesgada que inicie su estudio, a contrapelo del innominado "statu quo" actual.

Además de las obras de entretenimiento y de nueva planta, la Junta de Arbitrios mantiene a su costa la siguiente plantilla de empleados:
a) Un médico.
b) Un arquitecto.
c) Un secretario.
d) Un depositario.
e) Un aforador.
f) Un celador de obras.
g) Un guarda almacén.
h) Un capataz de sección de descarga.
i) Seis guardias municipales.
j) Once serenos y un suplente.
k) Un oficial encargado de servicios.
l) Un encargado de material de incendios.
m) Un farolero.
n) Un vigfa de mar.
o) Un conserje de cementerio.
p) Un guarda del cementerio.
q) Dos sepultureros.
r) Un maestro de niños.
s) Dos maestros (uno de niños y otro de niñas).
t) Tres auxiliares de escuelas. 
u) Un veterinario.

v) Un director del Centro Higiénico.

x) Un farmacéutico para el laboratorio.

y) Un ordenanza.

Desde su fundación, las sesiones de la Junta de Arbitrios eran cerradas, sin concurrencia de público. En enero de 1894, el General Arolas propuso que las sesiones fueran públicas y se dejara entrada libre a la prensa local. El asesor jurfdico se opuso terminantemente ante la ilegalidad que suponia dar carácter público a las sesiones celebradas por un organismo militar. Con este argumento queda reforzado el carácter de organismo exclusivamente militar de la Junta. Muy gráficamente, Pablo Parellada, corresponsal del Blanco y Negro durante la campaña de 1893 y militar de profesión, decía que la Junta de Arbitrios "más pareća consejo de guerra que concejo administrativo".

Con la llegada de las tropas expedicionarias todos los jefes de cuerpo, según reglamento pasan a ser vocales de la Junta, por lo que ésta, hasta septiembre de ese mismo afio, en que reembarcan parte ellos, acoge no menos de 18 miembros en cada sesión. A propuesta del General Cerero las antiguas comisiones se reducen a cuatro:

Mercado.-Reconocimiento de todos los géneros puestos a la venta, con el auxilio del Centro Higiénico.

Obras.-Proponer las mejoras que puedan introducirse en la plaza, tanto de obras como de reforma.

Hacienda.-Gestión de una buena administración.

Instrucción.-Instrucción pública (escuelas, condiciones que deben reunir, etc.).

La acumulación de tropas en Melilla trae como consecuencia ineludible la subida general de precios en la plaza. La intervención directa de la Junta en la fijación de precios estaba expresamente prohibida, por lo que aquélla se basará en un intento de influir en los precios aportando, por su gestión, artículos de consumo, con el fin de nivelarlos. Nos encontramos aquí con una de las constantes que pueden apreciarse en la actuación de la Junta en años sucesivos hasta su desaparición, puesto que las especiales condiciones de Melilla la hacían muy sensibles, en determinadas ocasiones, a acusadas variaciones de precios, generalmente al alza.

Al disminuir la guarnición con la marcha de la mayoría de las unidades expedicionarias que aún permanecían en Melilla, en septiembre de 1894, nuevamente se cambian las comisiones, que quedan de la siguiente forma:

- Policía y ornato (barrios del Polígono y Santiago).

- De Incendios.

- De Alumbrado.

- De Limpieza. 
- De Aguas.

- De Arbolado.

- De Instrucción Pública.

- De Aceras y Empedrado.

- De Higiene.

- Inspectora de Almacenes.

Una excesiva dispersión de comisiones que en la práctica funcionan como en el esquema anterior, más racional, y al que se volverá no mucho más tarde.

Como consecuencia del cambio en la guarnición permanente de Melilla -1895-, el General Alcántara, con nuevo reglamento, varía la composición de la Junta, que desde el 1 de junio de 1895, en que entra en vigor, se compone del General 2..$^{\circ}$ Jefe como Presidente, siendo los vocales el Comandante de Marina, el Jefe más caracterizado de Infanterfa, el Jefe del Escuadrón de Cazadores, el Director de Parques de Artillería, el Jefe del Detall de la Comandancia de Ingenieros, el Mayor de Plaza, el Teniente auditor de 1. ${ }^{a}$ clase, el Comisario de Guerra, el Director del Hospital, el Teniente Vicario Castrense y el Vicario eclesiástico, desapareciendo los tenientes coroneles y comandantes de los cuerpos -Regimientos de Africa números 1 y 4- que formaban parte de aquélla desde septiembre de 1894 .

La acumulación de proyectos de obras y servicios urgentes es tal que se propone la solicitud de un empréstito para llevarlos adelante, empréstito denegado por el Comandante General. Como anticipación de actuaciones futuras diremos que varios intentos posteriores de solicitud de empréstito resultaron también fallidos.

Con todo, se comienza la construcción del nuevo matadero al pie del cerro de San Lorenzo y a abonarse, lo que constituye una pesada carga para la Junta, los alquileres de viviendas de los oficiales destinados en la plaza. A finales de 1895 se inicia la construcción del cuartel de la Guardia Civil en el Mantelete, con cargo a la Junta, y seis meses más tarde se aprueba la construcción del nuevo mercado cubierto.

Desde 1896 se confeccionan los expedientes de reemplazo de los mozos locales, imposición del General Alcántara que motivó la primera seria discrepancia del elemento civil de la ciudad sujeto, según ellos, a los beneficios de plaza en permanente estado de guerra.

Por R. O. de 16 de enero de 1897 se reorganiza la Junta con nuevo reglamento por el que pasa a ocupar la presidencia el Comandante General, siendo vocales el General $2 .^{\circ}$ Jefe, el Jefe más caracterizado de Infantería, Jefe de Estado Mayor, los comandantes de Artillería de Ingenieros, de Marina y del Escuadrón de Caballería, el Auditor Militar, el Jefe de Sanidad, el Comisario de Guerra y el Teniente Vicario.

Aumenta la plantilla del personal auxiliar de la Junta en un momento en que ésta se encuentra con dificultades debido a la disminución de los 
ingresos por importaciones de tejidos, azúcar y otros artículos al haberse perdido la cosecha en el campo rifeño por la sequía. La creciente mendicidad procedente del territorio circundante obliga a la Junta a organizar y proporcionar una ayuda para socorrer y alimentar a los que llegan. Esto constituye un antecedente de lo que será otra constante a lo largo de muchos años: una beneficencia desbordada por las necesidades crecientes y acuciantes de una cierta población casi indigente, unas veces llegada del campo fronterizo y otras, las más, de las provincias andaluzas y levantinas ribereñas del Mediterráneo, lo que supondrá unos cuantiosos recursos distrafdos para este menester.

Por R. O. de 19 de julio de 1897 se emite un informe del consejo de Estado por el que se reconoce la existencia legal de la Junta de Arbitrios, paso necesario y previo a una futura integración de personal civil en un organismo al que aún no se le reconoce personalidad jurídica propia pero que al menos ha de cubrir las formas ante la expectativa de una próxima expansión urbana y poblacional que se adivina a corto plazo.

Hasta 1902, la Junta termina el mercado del Mantelete, instala la luz eléctrica en los barrios cercanos, levanta los pabellones del Buen Acuerdo en el Llano de Santiago e instala las casetas del Muro X interior. En ese momento la población de Melilla asciende a 6.000 personas. Aunque con gran espacio de terreno libre intermedio, la ciudad se extiende desde MeliUla la Vieja hasta las alturas de Santiago, y ha llegado el momento de cambiar la organización del ente municipal dando entrada en el mismo a personal civil, acabando parcialmente con la situación de tutela anterior, dando voz y voto a unos estamentos locales, que contribuyendo al sostenimiento del mu nicipio no intervienen en las decisiones sobre empleo de recursos y contratación de personal.

Por R. O. de 7 de abril de 1902, se reestructura la Junta que pasa a tener nueve vocales militares y nueve civiles, todos bajo la presidencia del General 2. ${ }^{\circ}$ Jefe. Entre los militares, el Coronel más antiguo de Infantería, Comandante de Artillerfa, Comandante de Ingenieros, Comandante de Marina, Jefe de Sanidad, Auditor, Comisario de Guerra, Teniente Vicario y Mayor de Plaza. Por los civiles, elegidos por gremios, tres propietarios, tres industriales, dos comerciantes y un profesional. Secretario, un civil con voz y sin voto. Todos ellos renovados cada dos años. Condición indispensable para ser miembro: tener la nacionalidad española; condición muy excluyente, aunque lógica, en una plaza con cerca de un tercio de extranjeros censados.

Como es fácil de apreciar de la composición de la nueva Junta, las futuras decisiones quedan demasiado claramente del lado del componente militar, lo que se ha de traducir en una queja repetidamente manifestada hasta la constitución del Ayuntamiento.

El reglamento es aprobado por R. O. de 5 de marzo de 1904. clara. 
mente inspirado, como los anteriores, en el de 1883.

Con su carácter cívico-militar, la Junta debe abandonar su antigua sede en el piso bajo izquierdo de la "Casa del Reloj", pertenciente a Guerra, pasando, en febrero de 1903, a la casa adjunta al Hospital Real, en el número 20 de la calle de la Iglesia, donde tuvo su sede el antiguo Círculo de la Amistad, hoy en proceso de derribo.

Se constituyen cuatro secciones, prácticamente similares a las anteriores, con algunos come tidos nuevos:

$1 .^{\mathrm{a}}$-Sección.-Obras, alumbrado y aguas.

2. ${ }^{a}$ Sección.-Censo, higiene, polića, espectáculos, beneficencia y mercado.

3. ${ }^{\text {a }}$ Sección.-Instrucción, religioso y cementerio.

4. ${ }^{a}$ Sección.-Presupuesto, contabilidad y aranceles.

Tras las elecciones, efectuadas el día 6 de junio, se aprecia un claro cambio de tono en las sesiones que se inician el dí 25 del mismo mes, cambio debido a la introducción de personas de distinto talante y personalidad entre el personal civil, menos propenso a consideraciones de jerarqu fa y disciplina. Destaca, sobre todo, la entrada, como miembro elegido por el gremio de propietarios, de Pablo Vallescá, quien aporta a las reuniones un ingrediente de discusión y discrepancia muy acusado. Pablo Vallescá, médico militar en situación de retirado, llegado a Melilla en 1882, aporta con sus intervenciones lo más destacado, quizá, de estas primeras sesiones.

En 1905, el presupuesto de la Junta llega a las 452.155 pesetas. Anteriormente ha adquirido los llamados pabellones de Orozco por los que debe abonar 300.000 pesetas, cantidad que, aunque a pagar en varios años, hipoteca gravemente el futuro, suscitando enconada polémica entre civiles y militares.

Desde 1893, a los cuatro barrios existentes se añaden la ampliación del Polígono (1896), barrio del Carmen (1897), de Santiago (1900), Buen Acuerdo (1902), Triana (1902), Alfonso XIII (1903) y Barrio Obrero (1905). Se confeccionan los primeros proyectos de urbanización, del Capitán Redondo, en 1904-5, cortos de alcance pero al menos una base para futuros planes. Todo ello supone una demanda de servicios urbanos muy superior a las posibilidades de la Junta, que tiene que actuar con carácter muy selectivo en la aplicación de sus reducidos medios financieros.

El estudio del aspecto financiero de la Junta de Arbitrios lleva consigo el del desarrollo económico de Melilla y su zona de influencia, pues ambos se siguen en relación de causa a efecto. Un incremento o disminución de importaciones y exportaciones se traduce en un incremento o disminución de ingresos por aforos $y$ en un avance o paralización de las iniciativas municipales. Su estudio es necesario para hacer inteligible el funcionamiento de la Corporación municipal.

Dado que el esquema orgánico de la Junta de Arbitrios permanece sinté- 
ticamente estable hasta 1927 no voy a pormenorizar sus iniciativas, muchas de las cuales están hoy todavia a la vista del ciudadano, por lo que comple to la reseña con algunas notas complementarias sobre su funcionamiento, con el obje to de no extender este obligadamente reducido estudio.

En 1909, motivado por los acontecimientos de julio, se produce un avance espectacular de la población de Melilla que de 12.000 habitantes al $1 .^{\circ}$ de enero pasa a tener 21.000 a finales de año. El 17 de diciembre de 1906 se habia colocado la primera piedra del nuevo barrio de Reina Victoria; al comenzar la campaña, el barrio apenas estaba construido en un 50 por 100 de su superficie, pero el incremento de población con demanda de vivienda y locales comerciales aceleró vertiginosamente la construcción, no solamente en el centro del llano, sino también en la zona exterior del campo donde crecen anárquicamente, en los alrededores de los campamentos, multitud de barracas y chabolas formando barriadas sin los más elementales servicios y que, con el paso del tiempo, por la ley de los hechos consumados, se habrán de convertir en barrios permanentes.

La campana de 1909 ha coincidido casi en el tiempo con el comienzo de la explotación de las minas de mineral de hierro en Beni-bu-Ifrur, con el inicio de las obras del puerto y con la ya advertida construcción urbana.

Es en esta situación cuando se aprueba el, en mi opinión, más importante plan de urbanización de Melilla -si se hubiese llevado a la práctica-, el de José de la Gándara, de mayo de 1910, por el cual se reconoce la situación preexistente y se intenta, bajo un programa razonable, reconducir el urbanismo de la ciudad. En poco tiempo se han creado excesivas necesidades de infraestructura muy superiores a las anteriormente existentes y que desbordan la capacidad de la Junta para solventarlas, aunque, por supuesto, esta misma expansión poblacional dará lugar a un aumento de recursos municipales al aumentar las importaciones de artículos sujetos a gravamen.

Por R. O. de 3 de julio de 1911 los hebreos y musulmanes nacionalizados pueden formar parte de la Junta de Arbitrios. Desde mayo de 1912, sus sesiones son abiertas al público.

$\mathrm{El}$ inevitable aume nto de plantilla de personal auxiliar y el imprescindible acercamiento al nuevo centro neurálgico de la ciudad aconsejan el traslado a nueva sede, traslado que se efectúa, desde el 30 de diciembre de 1911, al piso alto de la "Casa de Salama", en el Mantelete, en régimen de alquiler, régimen de todos los edificios ocupados por la Junta (escuelas, dependecias, etc.) al no poder tener patrimonio propio por carecer de personalidad jurfdica reconocida.

Durante los años de la primera guerra mundial, hay una importante disminución de ingresos como consecuencia de la paralización de las operaciones militares en la zona. Damos a continuación las cifras correspondientes a lo prespuestado y gastado durante los años que comprende la guerra: 


\begin{tabular}{ccc}
\hline Años & Presupuestado & Gastado \\
\hline 1914 & $1.569 .771,97$ & $1.663 .234,93$ \\
1916 & $1.970 .039,24$ & - \\
1917 & $1.620 .728,00$ & $1.551 .600,00$ \\
1918 & $1.489 .578,14$ & $1.371 .537,01$ \\
\hline
\end{tabular}

Nota: No se dan cifras correspondientes al año 1915 y gastado en 1916, datos no encontrados hasta la fecha.

En 1914 Melilla alcanza las 3.046 casas, 2.561 más que en 1902.

Por R. D. de 30 de diciembre de 1918 se crea el Ayuntamiento de Melilla, decreto que no llega a ponerse en práctica al oponerse algunos miembros de la Junta a que Melilla dependiera de Málaga, tal como se disponía en aquél.

Los ingresos por arbitrios se recuperan tras el reinicio de las operaciones militares en Marruecos desde 1919, llegando en 1920 a los 1.739.922,99 pesetas. Tras el comienzo de las operaciones de recuperación del territorio, despúes del desastre de julio de 1921, el aumento en los ingresos es muy significativo. Veamos unos años correspondientes a este período:

\begin{tabular}{lccc}
\hline Ejercicio & Presupuestado & Ingresado & Población \\
\hline $1922-3$ & - & $7.750 .355,24$ & 49.165 \\
$1923-4$ & $6.527 .938,45$ & $7.940 .181,52$ & - \\
$1924-5$ & $5.690 .759,00$ & $6.008 .739,70$ & - \\
$1925-6$ & $4.920 .982,40$ & 5.777 .294 .84 & - \\
$1926-7$ & $4.920 .682,40$ & $4.487 .236,74$ & - \\
1927.8 & $3.676 .334,40$ & - & - \\
$1928-9$ & $3.674 .983,45$ & - & - \\
1929.30 & $3.698 .490,52$ & - & 62.454 \\
\hline
\end{tabular}

En las cifras anteriores se observa, primeramente, el contraste con años anteriores, y en segundo lugar la disminución de ingresos a partir de 1924-5, años en los que el General Primo de Rivera dispone la paulatina disminución de tropas, centralización de algunas compras en la Península y el posterior desembarco de Alhucemas que lleva a aquella zona parte de la guarnición anteriormente en Melilla; terminada la campaña -1927-la repatriación se acelera y los ingresos disminuyen muy acusadamente.

Orgánicamente, desde el 20 de julio de 1924, la Junta de Arbitrios pasa a depender de la Oficina de Marruecos, lo que en cierto modo le hace perder parte de su carácter militar al dejar de depender del Ministerio de la Guerra. Todos los asuntos, lo que no deja de ser chocante para un te- 
rritorio de soberania, debían ser tratados a través de la Alta Comisaría en Tetuán. En marzo del año siguiente pasa a depender directamente de la Sección de Marruecos.

Un intento, en 1924, de cambiar el reglamento dando entrada a funcionarios del Estado y representación obrera, resultó fallido.

Imposible dar, ni aún resumido, una relación de obras y servicios a cargo de la Junta durante su período de vigencia. Solamente decir que su actuación fue causa de encendidas polémicas entre "projuntistas" y "antijuntistas", cada uno con su argumentación igualmente razonable, un signo más de la singularidad de la ciudad de Melilla en unos años en que se afirmaban las bases de la actual población, años en los que se daban al unísono un rápido $\mathrm{y}$ anormal crecimiento $\mathrm{y}$ unos hechos militares que lo propiciaban en unas condiciones que rara vez se han dado en la historia española.

Por R. D. de 14 de febrero de 1927, y con el fin de unificar los regimenes municipales de Ceuta y Melilla, se crea la Junta Municipal, con estatuto local de la misma fecha y compuesta por los siguientes vocales:

Un presidente, general o coronel en servicio activo de los destinados en la plaza.

Nueve vocales militares natos (?), de las distintas Armas y Servicios de los destinados en la plaza.

Cuatro vocales civiles natos, designados por el comandante general.

Trece vocales civiles electivos, elegidos por compromisarios que, a su vez, son elegidos por gremios y profesiones.

Igualmente número de suplentes militares y civiles.

La primera reunión de la Junta Municipal y última de la Junta de Arbitrios se dio el 14 de marzo de 1927, bajo la presidencia del Coronel de Intendencia, don Francisco Calvo Lucía, siendo nombrado vicepresidente don Cándido Lobera Girela.

La Junta se estructura en las siguientes secciones:

Gobernación y Cultura (Laboratorio, Farmacia, Servicios Sanitarios, Cementerios, Instrucción Primaria, Asesoría Jurídica, Asuntos Generales y Personal).

Hacienda (Presupuestos, Contabilidad, Depositaría, Censos y Padrones, Almacenes, Intervención e Investigación).

Fomento (Obras, Aguas, Alumbrado, Urbanización y Reformas anteriores).

Abastos (Matadero, Mercados, Pescadería y Polic fa de Subsistencias).

Policía Urbana (Limpieza y riegos, Bomberos, Tracción mecánica y de sangre, Talleres, Vialidad y Parques y Jardines).

El mando civil de la Alta Comisaría sobre las Juntas municipales se reconoce en el R. D. de 31 de octubre de 1927. Desde cinco días antes, Cándido Lobera ejerce como presidente interino, y desde el 16 de marzo si- 
guiente como presidente efectivo.

No cabe duda sobre el carácter provisional con que nació la Junta, pues ésta, como era de esperar, desaparece inmediatamente después de finalizada la dictadura de Primo de Rivera que le dio vida, tras hacerse cargo del Gobierno el General Berenguer. Al instante, todos los miembros de la Corporación pusieron sus cargos a disposición del Jefe de Gobierno, permaneciendo provisionalmente en sus puestos. Es, pese a todo, de justicia reseñar que su actuación fue memorable gracias a la dirección de Cándido Lobera, mérito que no le niegan ni siquiera sus adversarios, y en el que resalta su buena gestión financiera y la reorganización funcional basada en la eficacia.

Por R. D. de 10 de abril de 1930 se crea el Ayuntamiento de Melilla, permaneciendo interinamente los miembros de la anterior Junta a la expectativa de la convocatoria de las elecciones municipales.

El Real Decreto daba cuerpo legal al importante movimiento ciudadano que desde tiempo atrás postulaba una transformación del órgano municipal por la que tuviesen entrada todas las profesiones y clases sociales, coincidente aquél con un auge de las actividades políticas en la ciudad an teriormente la tentes $o$ inexistentes.

Tras la proclamación de la República, el 14 de abril de 1931, desaparece el excepcional anterior régimen local de la ciudad de Melilla, hermanándose, en esta función, con el resto de las ciudades españoles.

\section{BIBLIOGRAFIA Y DOCUMENTACION}

CIGES APARICIO, Manuel: España bajo la dinastía de los Borbones, Madrid, 1932.

DE MORALES, Gabriel: Datos para la Historia de Melilla, 1908.

LLANOS, Adolfo: Mebilla; historia de la campaña de Africa (18934), 1894.

Memorias de la Junta de Arbitrios.

Memoria de la Jun ta Municipal, 1927-30.

Padrones de Melilla, desde 1880.

Actas de la Junta de Arbitrios, desde 1879.

El Telegrama del Rif. Años 1903 a 1931. 